\title{
Characterization of Bacteria Isolation of Bacteria from Pinyon Rhizosphere, Producing Biosurfactants from Agro-Industrial Waste
}

\author{
ARNOLDO WONG-VILLARREAL ${ }^{1}$, LIZBETH REYES-LÓPEZ1 ${ }^{1}$ HIPÓLITO CORZO GONZÁLEZ1, \\ CRISTINA BLANCO GONZÁLEZ ${ }^{2}$ and GUSTAVO YÁÑEZ-OCAMPO ${ }^{2 *}$ \\ ${ }^{1}$ Agroalimentary Division, Forest Technological University, Ocosingo Chiapas, México \\ ${ }^{2}$ Environmental Technology Engeenering Academic Program, Polytechnic University of Chiapas, \\ Tuxtla Gutiérrez Chiapas, México
}

Submitted 12 June 2015, revised 9 September 2015, accepted 17 September 2015

\author{
Abstract
}

Two hundred and fifty bacterial strains were isolated from pinyon rhizosphere and screened for biosurfactants production. Among them, six bacterial strains were selected for their potential to produce biosurfactants using two low cost wastes, crude glycerol and lactoserum, as raw material. Both wastes were useful for producing biosurfactants because of their high content in fat and carbohydrates. The six strains were identified by $16 \mathrm{~S}$ rDNA with an identity percentage higher than $95 \%$, three strains belonged to Enterobacter sp., Pseudomonas aeruginosa, Bacillus pumilus and Rhizobium sp. All strains assayed were able to grow and showed halos around the colonies as evidence of biosurfactants production on Cetyl Trimethyl Ammonium Bromide agar with crude glycerol and lactoserum as substrate. In a mineral salt liquid medium enriched with both wastes, the biosurfactants were produced and collected from free cell medium after $72 \mathrm{~h}$ incubation. The biosurfactants produced reduced the surface tension from 69 to $30 \mathrm{mN} / \mathrm{m}$ with an emulsification index of diesel at approximately $60 \%$. The results suggest that biosurfactants produced by rhizosphere bacteria from pinyon have promising environmental applications.

Ke y words: agro-industrial wastes, biosurfactants, emulsification index, surface tension

\section{Introduction}

Biosurfactants (BS) are exopolymers mainly produced by bacteria, yeasts and fungi (Desai and Banat, 1997). BS are amphiphilic biomolecules, with hydrophobic and hydrophilic portions. The hydrophobic part of the molecule is based on saturated or unsaturated fatty acids. The hydrophilic portion can be either cationic and anionic amino acids or mono-, di-, and polysaccharides (Banat et al., 2000). Among the various species of BS, rhamnolipids have been studied extensively; they are among the most effective BS synthesized by Pseudomonas aeruginosa (Prieto et al., 2008). Some other BS widely known are surfactin produced by Bacillus subtilis, sophorolipids by Candida bombicola (Rosenber and Ron, 1999) and emulsan by Acinetobacter calcoaceticus (Karanth et al., 1999). Some Burkholderia $\mathrm{sp}$. have demonstrated to be very useful in producing a considerable diversity of glycolipids (Pérez et al., 2010).

BS reduce surface and interfacial tension at gasliquid-solid interfaces and have emulsification and foaming properties (Dubey et al., 2012; Freitas et al.,
2013; Vecino et al., 2013). BS have advantages over the highly used synthetic surfactants, such as lower toxicity or higher stability over extreme temperature, pressure, $\mathrm{pH}$ values and salinity conditions (Gudiña et al., 2013). Because of these advantages BS have extensive applications in oil recovery (Youssef et al., 2007), bioremediation of persistent organic pollutants, and also in industrial fields as food production and pharmaceutical (Banat et al., 2010; Ferhat et al., 2011; Fonseca et al., 2011).

Exploration of the microbial diversity of water and soil environments, along with the isolation and cultivation of biosurfactant-producing microorganisms (Makkar and Cameotra, 2002), are highly desired in order to enhance the biotechnological production of BS (Yañez-Ocampo and Wong-Villareal, 2013). The search for biosurfactant-producing microorganisms in the pinyon plant (Jatropha curcas L.) seems to have tremendous potential. This is primarily due to the natural ability of this plant to survive and grow under extreme environmental conditions, such as dryness and marginal soil (Abou-Kheira and Atta, 2009), and besides

* Corresponding author: G. Yáñez-Ocampo, Programa Académico de Ingeniería en Tecnología Ambiental, Universidad Politécnica de Chiapas, Tuxtla Gutiérrez, Chiapas, México Calle Eduardo J. Selvas s/n, Magisterial, 29082, Mexico; e-mail: gyanez@upchiapas.edu.mx 
the lack of knowledge about the interaction between microbes and pinyon roots.

Additionally, agro-industrial organic wastes has recently been used as substrate to cultivate BS due to its low cost and high availability (Cassidy and Hudak, 2001; Kitamoto et al., 2002; Abbasi et al., 2012; 2013). It is well known that wastes from palm oil, canola oil, soybean, glycerol and buttermilk, may be used to achieve an increase in production of about ten times in the mass of BS produced higher than that obtained when the production media contain glucose as the carbon source (Makkar and Cameotra, 2002). For instance, Ron and Rosenberg (2001) and Abbasi et al. (2012) demonstrated that BS can be produced by P. aeruginosa through fruit wastes, waste vegetable oil and foodindustry wastes as the substrate. In this context, agroindustrial wastes generated in Chiapas are low cost raw material, renewable and abundant throughout the year, with a total generation of about 28-140 thousand tons per year. These wastes include crops and processing residues of corn, coffee, cocoa, mango, banana, oil palm and buttermilk (SAGARPA, 2007; Valdéz-Vázquez et al., 2010). Likewise, huge amounts of glycerol were generated from the biodiesel fuel production in Chiapas during a 5 years operation period and, because this crude glycerol is expensive to purify for use in other industries, it remains without any disposal method and becoming a significant environmental problem, but potentially valuable as substrate to produce BS.

Hence, the isolation of bacteria strains from pinyon rhizosphere capable of biosurfactant production by using four agro-industrial wastes as substrate is of interest in commercial production. In the present study, the presence of potential biosurfactant producer bacteria was determined by the formation of a complex with $\mathrm{CTAB}$ with methylene blue as an indicator. Moreover, growth kinetics and BS production were described for those strains with potential biosurfactant producer properties. The surface tension and the emulsification index have also been measured. Finally, sequencing identification of 16S rRNA has also been used for bacterial identification.

\section{Experimental}

Materials and Methods

Agro-industrial waste material. Four different agro-industrial wastes were used as substrates to produce BS. Lactoserum, coffee husk and palm oil cake residues were obtained from the Ocosingo and Palenque regions of Chiapas in Mexico. Crude glycerol was obtained from biodiesel production process via transesterification of waste vegetable oil, also in Chiapas.
Physicochemical characterization of agro-industrial wastes. Nitrogen content was measured by Kjeldahl method and protein content was estimated using an appropriate Nitrogen Factor, carbohydrates were measured by a gravimetric method and fat content was measured gravimetrically after Soxhlet extraction using hexane as a solvent according to the procedures outlined in Standard Methods (APHA, 2001). The results were expressed as weight percent.

Isolation of bacterial strains from pinyon rhizosphere. Pinyon plants (Jatropha curcas L.) were collected from the municipality of Mazatán, Tapachula, Huixtla, Huehuetán, Mapastepec, Pijijiapan and Tonalá in the state of Chiapas, Mexico. From each sample, approximately $1 \mathrm{~g}$ of the plant root was first mixed with $9 \mathrm{ml}$ of $\mathrm{MgSO}_{4} \cdot 7 \mathrm{H}_{2} \mathrm{O} 10 \mathrm{mM}$ in tubes, and shaken vigorously to obtain a solution containing microorganisms from pinyon rhizosphere. Two hudred $\mu$ l of sample solution was then streaked on semisolid medium Baz (g/l): azelaic acid 2.0, $\mathrm{K}_{2} \mathrm{HPO}_{4} 0.4, \mathrm{KH}_{2} \mathrm{PO}_{4} 0.4$, $\mathrm{MgSO}_{4} \cdot 7 \mathrm{H}_{2} \mathrm{O} 0.2, \mathrm{CaCl}_{2} 0.02, \mathrm{Na}_{2} \mathrm{MoO}_{4} \cdot \mathrm{H}_{2} \mathrm{O} 0.002$, $\mathrm{FeCl}_{3} 0.01$, bromothymol blue 0.075 , agar 2.3 , pH 5.7 and incubated at $28^{\circ} \mathrm{C}$ for a week. Samples that showed bacterial growth were streaked twice again. Selected samples were inoculated in solid medium BAc: $0.2 \%$ azelaic acid, $0.02 \%$ L-citrulline, $0.04 \% \mathrm{~K}_{2} \mathrm{HPO}_{4}, 0.04 \%$ $\mathrm{KH}_{2} \mathrm{PO}_{4}, 0.02 \% \mathrm{MgSO}_{4} \cdot 7 \mathrm{H}_{2} \mathrm{O}$ (Estrada de los Santos et al., 2001) enriched with cyclohexamide (100 mg/l). After $7 \mathrm{~h}$ of incubation at $28^{\circ} \mathrm{C}$, colonies with different morphology were selected and further purified in BAc medium. To confirm the purity, isolates were transferred to PY medium (g/l): peptone 5, meat extract 3, agar 15. Purified colonies were prepared in $70 \%$ glycerol and stored at $-70^{\circ} \mathrm{C}$, to preserve them for further characterization.

Preliminary experiments to evaluate BS formation. Strains were transferred to PY agar (as activation medium), and incubated for $24 \mathrm{~h}$ at $30^{\circ} \mathrm{C}$. Subsequently, strains were inoculated again on CTAB agar $(\mathrm{g} / \mathrm{l})$ : $\mathrm{KH}_{2} \mathrm{PO}_{4} 0.7, \mathrm{Na}_{2} \mathrm{H}_{2} \mathrm{PO}_{4} \cdot 7 \mathrm{H}_{2} \mathrm{O}$ 1.7, $\left(\mathrm{NH}_{4}\right)_{2} \mathrm{SO}_{4} 2.32$, $\mathrm{MgSO}_{4} \cdot 7 \mathrm{H}_{2} \mathrm{O} 0.4$, hexadecyltrimethylammonium bromide (CTAB) 0.2 , agar base 15, agro-industrial waste 20 , methylene blue (MB) 0.03; with each agro-industrial waste, and incubated for $48 \mathrm{~h}$ at $30^{\circ} \mathrm{C}$. P. aeruginosa ATCC 27853 was used as a positive control. Bacterial colonies surrounded by a translucent halo were identified as a potential biosurfactant producer. The former, based on the property that BS can be determined by the formation of a complex with CTAB with methylene blue as indicator. In this method, methylene blue is reduced to methylene white by an excess of reducing sugar that generates translucent halos. The detection of the translucent halos formed due to complexation between anionic rhamnolipids and cationic MB/CTAB confirmed the presence of potential biosurfactant producer bacteria. 
Growth kinetics in liquid culture medium. Growth kinetics and BS production were described for those strains with potential biosurfactant producer bacteria. A pre-inoculum in PY medium was incubated at $30^{\circ} \mathrm{C}$ for $24 \mathrm{~h}$. For biomass collection, samples were centrifuged at $10.000 \times \mathrm{g}$ during $20 \mathrm{~min}$ at $4^{\circ} \mathrm{C}$. Growth kinetic was conducted in Erlenmeyer flask $(125 \mathrm{ml})$ containing $80 \mathrm{ml}$ aliquots of mineral salt media. For each strain, the mineral media was supplemented with $20 \mathrm{~g} / \mathrm{l}$ carbon source, from its respective agro-industrial residue, and the flasks were inoculated with a $1 \%(\mathrm{v} / \mathrm{v})$ inoculum. Kinetics were monitored for $72 \mathrm{~h}$. At regular intervals, samples were submitted to analysis of biomass by dry weight and to BS production by surface tension.

Surface tension measurement. BS production was quantified through the determination of surface tension. Culture samples were centrifuged at $15.000 \times \mathrm{g}$ for $20 \mathrm{~min}$ at $4^{\circ} \mathrm{C}$ to remove the cells and the supernatant was submitted to surface tension measurements. Surface tension was carried out by the Whilhelmy plate method using an Easy Dine KRÜSS K20 Tensiometer. This method consists in determining the force exerted on the liquid surface by a platinum plate until it penetrates a certain depth from the liquid surface and breaks the interfacial surface tension. For the measurements, distilled water was used as a control with a surface tension of $66-67 \mathrm{mN} / \mathrm{m}$.

Emulsification Index (EI $\left.{ }_{24} \%\right)$. The emulsification index of culture samples was determined by adding $2 \mathrm{ml}$ of cell-free supernatant to $2 \mathrm{ml}$ of diesel in a test tube, mixing with a vortex for $1 \mathrm{~min}$ and leaving to stand for $24 \mathrm{~h}$ at environmental temperature. Emulsions formed by the isolates were compared to those formed by Sodium Dodecyl Sulfate (SDS) 5\% (w/v) as control. The emulsification index was calculated by dividing the height of the emulsion layer $\left(\mathrm{H}_{\mathrm{E}}\right)$ by the total height of the mixture $\left(\mathrm{H}_{\mathrm{T}}\right)$ and multiplying by 100 , as following: $\mathrm{EI}_{24}(\%)=\left(\mathrm{H}_{\mathrm{E}} / \mathrm{H}_{\mathrm{T}}\right)^{\star} 100$. Finally, $\mathrm{EI}_{24}$ was carried out at the beginning of the test and $24 \mathrm{~h}$ later, to confirm its stability through time (Abbasi et al., 2011).

All experimental measurements were performed in triplicate, data were averaged and was calculated standard deviation using Minitab ${ }^{\varpi} 17$ software package.

Sequencing identification of $16 \mathrm{~S}$ rRNA. $16 \mathrm{~S}$ ribosomal RNA gene was amplified by using $\mathrm{rD1}$ and $\mathrm{fD} 1$ oligonucleotides according to conditions described by Saitou and Nei (1987) and Weisburg et al. (1991). The amplification products were purified in gel using the purification kit GeneJET (Thermo Scientific). The purified products were sent for sequencing construction to the Sequencing Unit at the Biotechnology Institute of the National Autonomous University of Mexico (UNAM). Sequence of the 16S rRNA isolates were compared with 16S rRNA genes from the GenBank database.

\section{Results}

Physicochemical characterization of agro-industrial residues. Agro-industrial residues were analysed to determine its composition. Protein, carbohydrate and fat content were quantified from lactoserum, coffee husk, palm oil cake and crude glycerol residues (Table I). Crude glycerol showed the highest carbohydrate content among the four residues.

Strains selection from preliminary detection of biosurfactant assays. Two hundred fifty bacterial strains from pinyon rhizosphere were isolated and further inoculated on CTAB agar using lactoserum, coffee husk, palm oil cake and crude glycerol residues. Blue methylene was used as indicator of BS production. Translucent halos were detected in six strains from lactoserum and crude glycerol residues, demonstrating the presence of BS. Strains were named based on the agro-industrial residue that allowed the evident halo presence. Strains showing halo in lactoserum were named LS1, LS8 and LS147; strains showing a halo in crude glycerol were named CG12, CG18 and CG101 (Table II).

Growth kinetics in liquid culture medium with CG and LS. Growth kinetics were carried out in liquid culture medium with lactoserum and crude glycerol using LS1, LS8, LS147 strains and CG12, CG18, CG101 strains respectively. As shown in Fig. 1, the exponential growth of biomass from CG18 strains was observed and the maximum biomass $(2.1 \mathrm{~g} / \mathrm{l})$ was reached at $48 \mathrm{~h}$ of cultivation; while the maximum growth of biomass using lactoserum was reached at $48 \mathrm{~h}$ of cultivation with LS8 strain $(1.34 \mathrm{~g} / \mathrm{l})$. All strains showed typical bacterial growth with both agro-industrial wastes.

Surface tension and emulsification index. BS production was quantified by surface tension measurements and emulsification index using diesel as hydrophobic

Table I

Physicochemical analysis of agro-industrial wastes

\begin{tabular}{|l|c|c|c|c|}
\hline \multirow{2}{*}{$\begin{array}{c}\text { Physicochemical } \\
\text { parameter }(\%)\end{array}$} & \multicolumn{4}{|c|}{ Agro-industrial wastes } \\
\cline { 2 - 5 } & Lactoserum & Crude glycerol & Coffee waste & Oil palm cake \\
\hline Proteins & $0.54 \pm 0.06$ & $0.93 \pm 0.013$ & $0.94 \pm 0.06$ & $2.59 \pm 0.13$ \\
\hline Carbohydrates & $7.03 \pm 0.024$ & $31.76 \pm 0.15$ & $21.21 \pm 0.00$ & $12.84 \pm 0.00$ \\
\hline Fats and oils & $4.23 \pm 0.36$ & $53.69 \pm 0.136$ & $2.7 \pm 0.64$ & $6.6 \pm 0.09$ \\
\hline
\end{tabular}


Table II

Test result of BS presence on agar CTAB and agro-industrial waste

\begin{tabular}{|l|c|c|c|c|c|c|c|}
\hline \multirow{2}{*}{$\begin{array}{c}\text { Agar CTAB and } \\
\text { agro-industrial waste }\end{array}$} & \multicolumn{6}{|c|}{ Bacterial strains isolated from pinyon rhizosphere } \\
\cline { 2 - 8 } & LS1 & LS8 & LS147 & CG12 & CG18 & CG101 & PA \\
\hline Lactoserum & + & + & + & - & - & - & - \\
\hline Crude glycerol & NC & NC & NC & + & + & + & + \\
\hline Coffee husk & - & - & - & NC & NC & NC & NC \\
\hline Oil palm cake & - & - & - & NC & NC & NC & NC \\
\hline
\end{tabular}

$\mathrm{PA}=$ Pseudomonas aeruginosa $\mathrm{ATCC} 27853 . \mathrm{NC}=$ no growth.$+=$ positive response and halo presence. - = negative response, growth without halo

phase $\left(\mathrm{EI}_{24} \%\right)$. Cell-free supernatant from lactoserum and crude glycerol culture samples were analysed. Figures $2 \mathrm{~A}$ and $2 \mathrm{~B}$ showed the response surfaces determined at $72 \mathrm{~h}$ of the growth kinetic assays. The results obtained showed that BS produced by CG12, CG18 and CG101 strains reduced the surface tension to $28-30 \mathrm{mN} / \mathrm{m}$, meanwhile LS1, LS8 and LS147 strains reduced the surface tension to $38-43 \mathrm{mN} / \mathrm{m}$. On the other hand, emulsification activity was quantified by determining $\mathrm{EI}_{24} \%$. The biosurfactants produced by lactoserum strains showed emulsification index values of 44 to $69 \%$ whereas BS produced by crude glycerine strains showed $\mathrm{EI}_{24}$ values of 5 and $26 \%$.

Sequencing of 16S rRNA gene. Sequencing of $16 \mathrm{~S}$ rDNA showed that strain LS1 was closely related to Enterobacter sp. CIFRI D-TSB-9-ZMA, strain LS8 to Enterobacter sp., strain LS147 to $P$. aeruginosa SWD, strain CG12 to B.pumilus OCOB5, strain CG18 to Rhizobium sp. BGC8 and finally, strain CG101 was related to Enterobacter sp. NCCP-291 (table III).
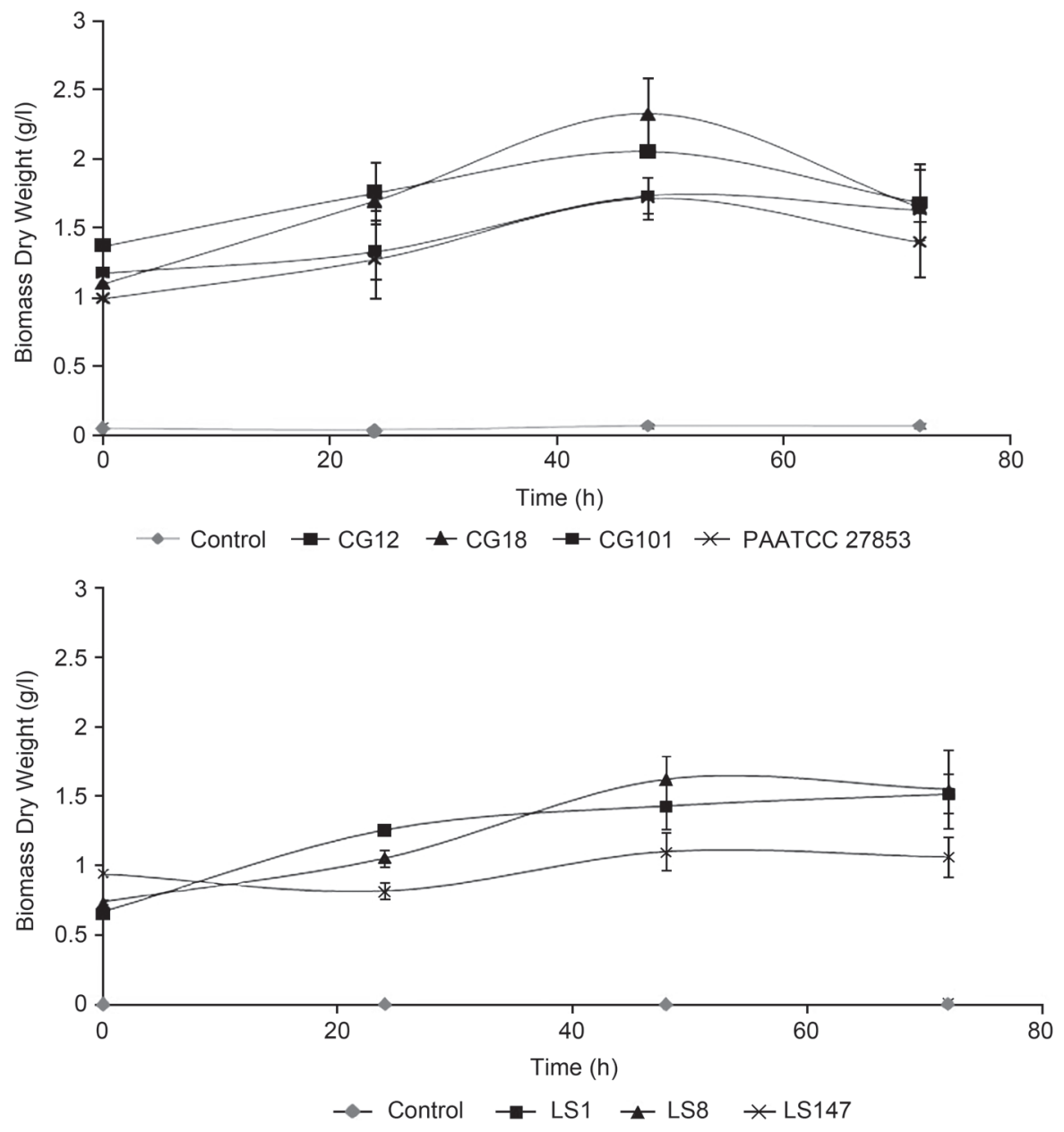

Fig. 1. Growth of CG and LS strains during cultivation at $30^{\circ} \mathrm{C}$ in a culture medium with mineral salts, crude glycerol (up) and lactoserum (down) as carbon source 

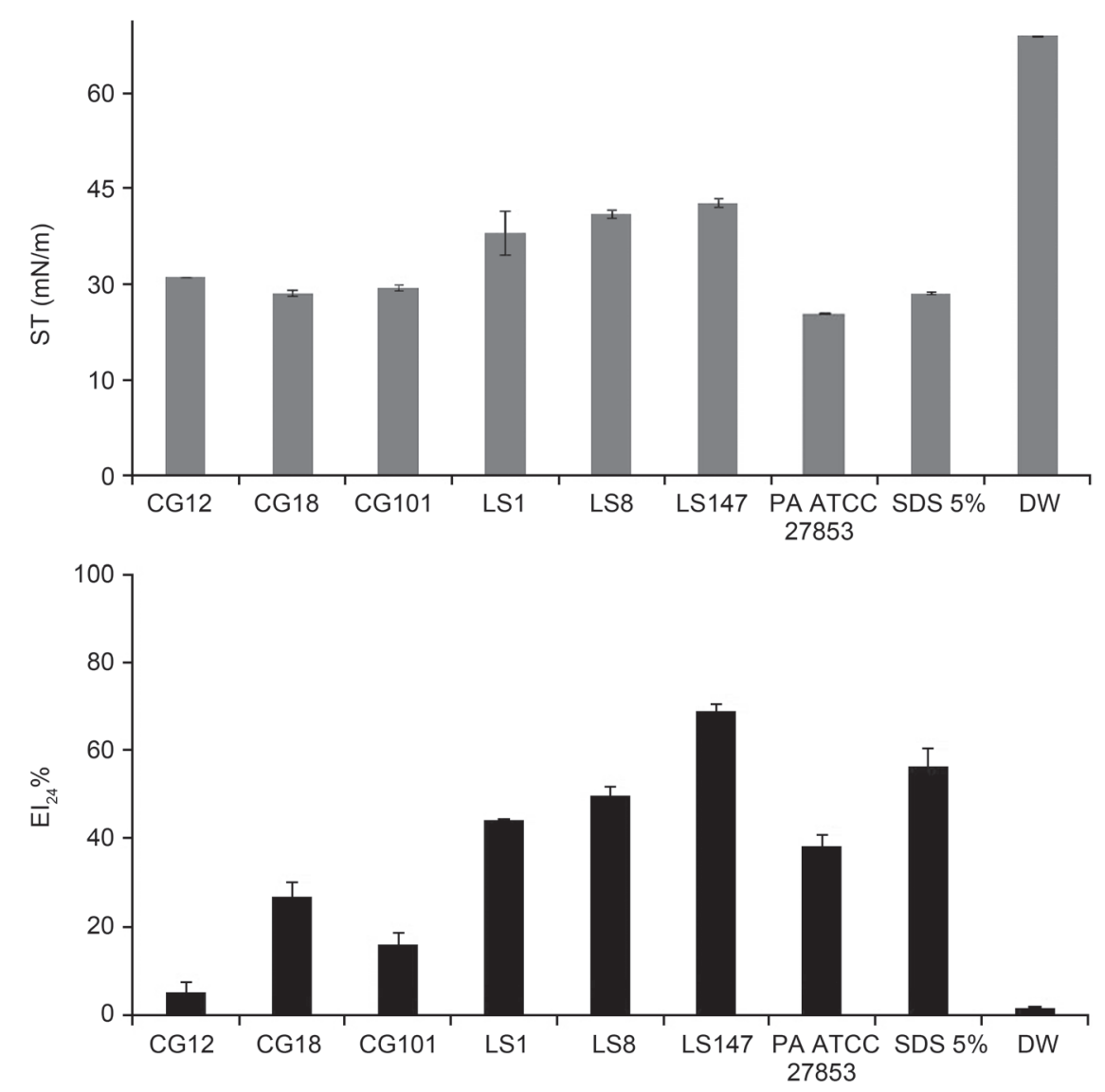

Fig. 2. Surface tension and emulsification index of BS from CG and LS strains, after $72 \mathrm{~h}$ incubation. $\mathrm{ST}=$ surface tension (up). $\mathrm{EI}_{24} \%=$ emulsificaton index (down). PA ATCC $27853=$ P. aeruginosa reference strain. SDS $=$ Sodium Dodecyl Sulfate. DW = Distilled water

\section{Discussion}

It is estimated that the raw material accounts for $30-40 \%$ of the total production cost in most biotechnological processes (Liu et al., 2011; Pereira et al., 2013). In order to reduce cost for biosurfactants production at industrial scale, it is desirable to use low cost raw materials (Jain et al., 2013a; 2013b). In this paper, crude glycerol and lactoserum wastes, due to their content in fat and carbohydrates, were used as carbon source for biosurfactant production by bacteria. According to Gudiña et al. (2015), the high nutritional content

Table III

Molecular characterization by $16 \mathrm{~S}$ rDNA gene and the percentage of identity of the bacterial strains isolated from pinyon rhizosphere

\begin{tabular}{|l|l|c|}
\hline Strain code & \multicolumn{1}{|c|}{ Name of specie } & \% Identity \\
\hline LS1 & Enterobacter sp. CIFRI D-TSB-9-ZMA & 95 \\
\hline LS8 & Enterobacter sp. & 95 \\
\hline LS147 & P. aeruginosa SWD & 96 \\
\hline CG12 & B. pumilus OCOB5 & 97 \\
\hline CG18 & Rhizobium sp. BGC8 & 98 \\
\hline CG101 & Enterobacter sp. NCCP-291 & 93 \\
\hline
\end{tabular}

of both substrates, along with their low price, make them useful to be used as culture medium or nutrient supplements for microorganisms in diverse industrial fermentation processes.

In contrast, the low content in fat and carbohydrate in coffee husk and palm oil cake wastes, do not suggest that they can be used as raw material for BS production (Makkar and Cameotra, 2002). There are few reports on utilizing these wastes to BS production by microorganisms (Jain et al., 2013a; 2013b; Rocha e Silva et al., 2014).

In the CTAB agar test for tensoactive agents, growth and presence of halo around bacterial colonies of LS1, LS8, LS147, CG12, CG18 and CG101 strains was observed. However, on CTAB agar with coffee husk and palm oil cake wastes, LS strains grew but there was no halo. Same behaviour was observed with CG strains on lactoserum, there was no evidence of a halo. This suggests that thecarbon source from both wastes, employed for synthesis of biomass.

CTAB agar, is a selective culture medium that confirms glycolipids presence. This medium has been used for anionic biosurfactants detection like rhamnolipids produced by Pseudomonas sp. (Siegmund and Wagner, 1991; Soberón-Chavez et al., 2005; Smyth et al., 
2010). In the CTAB agar assay, the strain P.aeruginosa ATCC 27853 was employed as positive control, so probably the BS produced by CG and LS strains are glycolipidic nature.

The LS strains were not capable to grow on crude glycerol. Probably impurities from crude glycerol produced an inhibitory growth effect. According to da Silva et al. (2009), Fonseca et al. (2009; 2011), glycerol is a biodegradable molecule by aerobic or anaerobic pathway, however because its alkalinity and impurities, it is necessary to neutralize and filter it, in order that microorganisms can use it as carbon source. Liu et al. (2011) and Rywinska et al. (2013) have reported alkali $12-16 \%$, methyl esther $15-18 \%$, methanol $8-12 \%$ and water $2-3 \%$ as glycerin impurities.

During the kinetics performed in liquid medium with crude glycerol and lactoserum, the strains CG and LS had a typical microbial behaviour growth. In stationary growth phase $(50 \mathrm{~h})$, the quantity of biomass, in dry weight, for CG12, CG18 and CG101 strains was 1.51, $1.54,1.06 \mathrm{~g} / \mathrm{l}$ respectively, whereas LS1, LS8 and LS147 strains produced $1.31,1.34$ y $0.84 \mathrm{~g} / 1$ respectively. These results indicate that the bacterial strains isolated from pinyon rhizosphere are capable to grow on crude glycerol and lactoserum, as the only carbon source.

In parallel with kinetic growth, the surface tension (ST) from cell-free supernatants was quantified in order to evidence BS production. The CG strains reduced ST between $28-30 \mathrm{mN} / \mathrm{m}$ and LS strains between 38-42 mN/m. Gudiña et al. (2015) and Al-Bahry et al. (2013) also used ST to show BS production in a liquid medium with molasses as carbon source, in which B. subtilis and P. aeruginosa were grown. The ST reported by both authors was 23 and $30 \mathrm{mN} / \mathrm{m}$ respectively.

The emulsification indexes of cell-free supernatants showed that BS produced by the bacterial strains isolated from pinyon rhizosphere, have emulsifier properties stable by 24 hours (strains CG 5-26\% and strains LS 44 a 69\%). The ability to form stable emulsions is an important feature to be considered for the application of biosurfactants, mainly for environmental applications such as bioremediation and enhanced oil recovery (Gudiña et al., 2015).

BS produced by CG and LS strains cultured with crude glycerol and lactoserum had a similar behaviour in ST and $\mathrm{EI}_{24} \%$, to positive controls: BS from P. aeruginosa ATCC $27853\left(25 \mathrm{mN} / \mathrm{m}, 38 \mathrm{EI}_{24} \%\right)$ also synthetic surfactant SDS 5\% (29 mN/m, 56 $\left.\mathrm{EI}_{24} \%\right)$. Distilled water was used as negative control $\left(69 \mathrm{mN} / \mathrm{m}, 1.2 \mathrm{EI}_{24} \%\right)$. Thus, a cell-free broth-containing biosurfactant can be directly used without purification steps, which would further reduce the biosurfactant production cost (Déziel et al., 1999). Biosurfactants produced by CG and LS strains, can be applied in enhanced oil recovery. Similar results were obtained by Nalini and Parthasarathi (2014).
In this study, two hundred and fifty strains were isolated from the pinyon rhizosphere of plants collected in Chiapas. Six of them demonstrated potential biosurfactant production. It was evident that crude glycerol and lactoserum are wastes that can be used as raw material for biosurfactant production. These BS can reduce the surface tension and emulsify diesel. The strains CG12 and CG18 identified as B. pumilus OCOB5 and Rhizobium sp. BGC8 are not yet reported as biosurfactants producers. The results are of great interest for biotechnology applications in bioremediation of heavy metals, hydrocarbons and pesticides (Sastoque-Cala et al., 2010). They suggested that strains that showed BS are also capable to solubilize phosphates, grow in insoluble carbon sources such as benzene and phenol and, at the same time, desorb heavy metals in soil.

\section{Acknowledgments}

The authors would like to express their gratitude to Consejo Nacional de Ciencia y Tecnología (CONACYT) and Secretaría de Educación Pública (SEP) from Mexico, for the financial support for the development of this research (project number 177487).

\section{Literature}

Abbasi H., M. Hamedi, T.B. Lotfabad, H.S. Zahiri, H. Sharafi, F. Masoomi, A. Moosavi-Movahedi, A. Ortiz, M. Amanlou and K. Noghabi. 2012. Biosurfactant-producing bacterium, Pseudomonas aeruginosa MA01 isolated from spoiled apples: Physicochemical and structural characteristics of isolated biosurfactant. J. Biosci. Bioeng. 113: 211-219.

Abbasi H., K.A. Noghabib, M.M. Hamedia, H.S. Zahiri, A.A. Moosavi-Movahedi, M. Amanlou, J.A. Teruel and A. Ortiz. 2013. Physicochemical characterization of a monorhamnolipid secreted by Pseudomonas aeruginosa MA01 in aqueous media. An experimental and molecular dynamics study. Coll. Surf. B: Biointerf. 101: 256-265.

Abou-Kheira A. and N. Atta. 2009. Response of Jatropha curcas L. to water deficit: Yield, water use efficiency and oilseed characteristics. Biomass Bioenerg. 33: 1343-1350.

APHA. 2001. Revisions to Standard Methods for the Examination of Water and Wastewater, Washington, DC.

Al-Bahry S.N., Y.M. Al-Wahaibi, A.E. Elshafie, A.S. Al-Bemani, S.J. Joshi, H.S. Al-Makhmari and H.S. Al-Sulaimani. 2013. Biosurfactant production by Bacillus subtilis B20 using date molasses and its possible application in enhanced oil recovery. Int. Biodeterior. Biodegradation. 81: 141-146.

Banat I., R. Makkar and S. Cameotra. 2000. Potential commercial applications of microbial surfactants. Appl. Microbiol. Biotechnol. 53: 495-508.

Banat I., A. Franzetti, I. Gandolfi, G. Bestetti, M. Martinotti, J. Letizia, T. Smyth and R. Marchant. 2010. Microbial biosurfactants production, applications and future potential. Appl. Microbiol. Biotechnol. 87: 427-444.

Cassidy D. and A. Hudak. 2001. Microorganism selection and biosurfactant production in a continuously and periodically operated bioslurry reactor. J. Hazard. Mater. B84: 253-264.

da Silva G.P., M. Mack and J. Contiero. 2009. Glycerol: A promising and abundant carbon source for industrial microbiology. Biotechnol. Adv. 27: 30-39. 
Desai J. and I. Banat. 1997. Microbial production of surfactants and their commercial potential. Microbiol. Mol. Biol. Rev. 61: 47-64. Déziel E., F. Lepine, D. Dennie, D. Boismenu, O. Mamer and R. Villemur. 1999. Liquid chromatography/mass spectrometry analysis of mixtures of rhamnolipids produced by Pseudomonas aeruginosa strain 57RP grown on mannitol or naphthalene. Biochim. Biophys. Acta. 1440: 244-252.

Dubey K.V., P.N. Charde, S.U. Meshram, L.P. Shendre, V.S. Dubey and A.A. Juwarkar. 2012. Surface-active potential of biosurfactants produced in curd whey by Pseudomonas aeruginosa strain-PP2 and Kocuria turfanesis strain-J at extreme environmental conditions. Bioresour. Technol. 126: 368-374.

Estrada de los Santos P., R. Bustillos-Cristales and J. CaballeroMellado. 2001. Burkholderia, a genus rich in plant-associated nitrogen fixers with wide environmental and geographic distribution. Appl. Environ. Microbiol. 67: 2790-2798.

Ferhat S., S. Mnif, A. Badis, K. Eddouaouda, R. Alouaouic, A. Boucherit, N. Mhiri, N. Moulai-Mostefa and S. Sayadi. 2011 Screening and preliminary characterization of biosurfactants produced by Ochrobactrum sp. 1C and Brevibacterium sp. 7G isolated from hydrocarbon-contaminated soils. Int. Biodeterior. Biodegradation. 65: 1182-1188.

Fonseca P.F., T.F. Ferreira, G. Cardoso Fontes and M.A. Zarur Coelho. 2009. Glycerol valorization: New biotechnological routes. Food Bioprod. Process. 87: 179-186.

Fonseca A., D.S. Teodoro-Martinez, G. Nazareno, B. Gontijo, Í. Serrano, J.S. Garcia, M.R. Tótolac, M.N. Eberlin, M. Grossmand, O.L. Alves and others. 2011. Production and structural characterization of surfactin (C14/Leu7) produced by Bacillus subtilis isolate LSFM-05 grown on raw glycerol from the biodiesel industry. Process Biochem. 46: 1951-1957.

Freitas D., Í. Lima, A. Nogueira, J. Lima, M. Aparecida, V. Melo and L. Barros. 2013. Kinetic study of biosurfactant production by Bacillus subtilis LAMI005 grown in clarified cashew apple juice. Colloids Surf. B Biointerfaces. 101: 34-43.

Gudiña E., J. Pereira, R. Costa, J. Coutinho, J. Teixeira and L. Rodríguez. 2013. Biosurfactant-producing and oil-degrading Bacillus subtilis strains enhance oil recovery in laboratory sandpacked columns. J. Hazard. Mater. 261: 106-113.

Gudiña E.J., A.I. Rodrigues, E. Alves, M.R. Domingues, J.A. Teixeira and L.R. Rodrigues. 2015. Bioconversion of agro-industria by-products in rhamnolipids toward applications in enhanced oil recovery and bioremediation. Bioresour. Technol. 177: 87-93.

Jain R.M., K. Modya, N. Joshi, A. Mishra and B. Jha. 2013a. Production and structural characterization of biosurfactant produced by an alkaliphilic bacterium, Klebsiella sp.: Evaluation of different carbon sources. Colloids Surf. B Biointerfaces. 108: 199-204.

Jain R.M., M. Kalpana, J. Nidhi, M. Avinash and J. Bhavanath. 2013b. Effect of unconventional carbon sources on biosurfactant productionand its application in bioremediation. Int. J. Biol. Macromol. 62: 52-58.

Karanth N.G.K., P.G. Deo and N.K. Veenanadig. 1999. Microbial production of biosurfactants and their importance. Curr. Sci. 77: 116-125.

Kitamoto D., H. Isoda and T. Nakahara. 2002. Functions and potential applications of glycolipid biosurfactants from energy-saving materials to gene delivery carriers. J. Biosc. Bioeng. 94: 187-201.

Liu Y., M. Chong, J. Koh and L. Ji. 2011. Bioconversion of crude glycerol to glycolipids in Ustilago maydis. Bioresour. Technol. 102: 3927-3933.

Makkar R.S. and S.S. Cameotra. 2002. An update on the use of unconventional substrates for biosurfactant production and their new applications. Appl. Microbiol. Biotechnol. 58: 428-434.
Nalini S. and R. Parthasarathi. 2014. Production and characterization of rhamnolipids produced by Serratia rubidaea SNAU02 under solid-state fermentation and its application as biocontrol agent. Bioresour. Technol. 173: 231-238.

Pereira A.G., G.J. Pacheco, L.F. Tavares, B.C. Neves, F.A. Kronemberger, R.S. Reis and D.M.G. Freire. 2013. Optimization of biosurfactant production using waste from biodiesel industry in a new membrane assisted bioreactor. Process Biochem. 48: 1271-1278.

Pérez J., O. Anaya, C. Chang, I. Membrillo and G. Calva. 2010. Biosurfactants production by free-living bacteria nitrogen fixers growing on hydrocarbon (in Spanish). Rev. CENIC Cienc. Quím. 41: 1-9. Prieto L.M, M. Michelon, J.F.M. Burkert, S.J. Kalil and C.A.V. Burkert. 2008. The production of rhamnolipid by a Pseudomonas aeruginosa strain isolated from a southern coastal zone in Brazil. Chemosphere. 71: 1781-1785.

Rocha e Silva N.M.P., R.D. Rufino, J.M. Luna, V.A. Santos and L.A. Sarubbo. 2014. Screening of Pseudomonas species for biosurfactant production using low-cost substrates. Biocatal. Agric. Biotechnol. 3: 132-139.

Ron E. and E. Rosenberg. 2001. Natural roles of biosurfactants. Environ. Microbiol. 3: 229-236.

Rosenberg E. and E. Ron. 1999. High- and low-molecular-mass microbial surfactants. Appl. Microbiol. Biotechnol. 52: 154-162.

Rywinska A., P. Juszczyk, M. Wojtatowicz, M. Robak, Z. Lazar, L. Tomaszewska and W. Rymowicz. 2013. Glycerol as a promising substrate for Yarrowia lipolytica biotechnological applications. Biomass bioenergy 48: 148-166.

SAGARPA. Secretaría de Agricultura, Ganadería, Desarrollo Rural, Pesca y Alimentación. 2007. Servicio de Información Agroalimentaria y Pesquera (SIAP) (México). Disponible en: http://www.siap. sagarpa.gob.mx/. 2015.06.10.

Saitou N. and M. Nei. 1987. The Neiighbor-joining method: a new method for reconstructiong phylogenetic trees. Mol. Biol. Evol. 4: 406-425.

Sastoque-Cala L., A.M. Cotes-Prado and A.M. Pedroza-Rodríguez. 2010. Effect of nutrients and fermentation conditions on the production of biosurfactants using rhizobacteria isolated from fique plants. Universitas Scientiarum. 15: 251-264.

Siegmund I. and F. Wagner. 1991. New method for detecting rhamnolipids excreted by Pseudomonas species during growth on mineral agar. Biotechnol. Tech. 5: 265-268.

Smyth T., A. Perfumo, R. Marchant and I. Banat. 2010. Isolation and analysis of low molecular weight microbial glycolipids, pp. 3705-3723. In: Timmis K.N. (ed.). Handbook of hydrocarbon and lipid microbiology. Springer, Berlin.

Soberón-Chávez G., F. Lépine and E. Déziel. 2005. Production of rhamnolipids by Pseudomonas aeruginosa. Appl. Microbiol. Biotechnol. 68: 718-725.

Valdez-Vazquez I., J.A. Acevedo-Benítez and C. Hernández-Santiago. 2010. Distribution and potential of bioenergy resources from agricultural activities in Mexico. Ren. Sust. Ener. Rev. 14: 2147-2153. Vecino X., R. Devesa-Rey, J. Cruz and A. Moldes. 2013. Evaluation of biosurfactant obtained from Lactobacillus pentosus as foaming agent in froth flotation. J. Environ. Manage. 128: 655-660.

Weisburg W., G. Barns, D.A. Pelletier and D.J. Lane. 1991. 16S ribosomal DNA amplification for phylogenetic study. J. Bacteriol. 173: 697-670.

Yañez-Ocampo G. and A. Wong-Villareal. 2013. Microbial biosurfactants, potential production with agroindustrial wastes of Chiapas (in Spanish). Bio Tecnología 17: 12-28.

Youssef N., D. Simpson, K. Duncan, M. McInerney, M. Folmsbee, T. Fincher and R. Knapp. 2007. In situ biosurfactant production by Bacillus strains injected into a limestone petroleum reservoir. Appl. Environ. Microbiol. 73: 1239-1247. 
